\title{
A 9-year follow-up of a self-management group intervention for persistent neck pain in primary health care: a randomized controlled trial
}

This article was published in the following Dove Press journal:

Journal of Pain Research

30 December 2016

Number of times this article has been viewed

\author{
Catharina Gustavsson ${ }^{1,2}$ \\ Lena von Koch 1,3,4 \\ 'Center for Clinical Research Dalarna, \\ Department of Public Health and \\ Caring Science, Uppsala University, \\ Uppsala, ${ }^{2}$ School of Education, Health \\ and Social Studies, Dalarna University, \\ Falun, ${ }^{3}$ Department of Neurobiology, \\ Care Science and Society, Karolinska \\ Institutet, ${ }^{4}$ Department of Neurology, \\ Karolinska University Hospital, \\ Stockholm, Sweden
}

Background and objective: In previous short-term and 2-year follow-ups, a pain and stress self-management group intervention (PASS) had better effect on pain-related disability, selfefficacy, catastrophizing, and perceived pain control than individually administered physiotherapy (IAPT) for patients with persistent tension-type neck pain. Studies that have evaluated long-term effects of self-management approaches toward persistent neck pain are sparse. The objective of this study was to compare pain-related disability, self-efficacy for activities of daily living (ADL), catastrophizing, pain, pain control, use of analgesics, and health care utilization in people with persistent tension-type neck pain 9 years after they received the PASS or IAPT. Materials and methods: Of 156 people (PASS, $n=77$; IAPT, $n=79$ ) originally included in a randomized controlled trial, 129 people (PASS, $n=63$; IAPT, $n=66$ ) were eligible and were approached for the 9-year follow-up. They were sent a self-assessment questionnaire, comprising the Neck Disability Index, the Self-Efficacy Scale, the Coping Strategies Questionnaire, and questions regarding pain, analgesics, and health care utilization. Mixed linear models for repeated measures analysis or generalized estimating equations were used to evaluate the differences between groups and within groups over time (baseline, previous follow-ups, and 9-year follow-up) and the interaction effect of "time by group".

Results: Ninety-four participants $(73 \%)$ responded (PASS, $n=48$; IAPT, $n=46$ ). At 9 years, PASS participants reported less pain-related disability, pain at worst, and analgesics usage, and a trend toward better self-efficacy compared to IAPT participants. There was a difference between groups in terms of change over time for disability, self-efficacy for ADL, catastrophizing, perceived pain control, and health care visits in favor of PASS. Analyses of simple main effects at 9 years showed that the PASS group had less disability $(p=0.006)$ and a trend toward better self-efficacy ( $p=0.059)$ than the IAPT group.

Conclusion: The favorable effects on pain-related disability of PASS were sustained 9 years after the intervention.

Keywords: activities of daily living, disability, musculoskeletal pain, self-efficacy, selfmanagement, tension-type neck pain

\section{Introduction}

Musculoskeletal neck pain of extended duration is common, affecting approximately one-fifth of the adult population. ${ }^{1,2}$ Of people who experience neck pain at some time point, almost $50 \%$ will report recurring or persistent pain complaints some years later. ${ }^{3,4}$

Founded in a biopsychosocial perspective on pain, there is a growing awareness of the significance of applying cognitive-behavioral principles in pain rehabilitation in primary health care (PHC) ${ }^{5,6}$ Rehabilitation strategies that address cognitive and behavioral factors involved in the maintenance of musculoskeletal pain by promoting active
Correspondence: Catharina Gustavsso Center for Clinical Research Dalarna, Nissers vag 3, S-79182 Falun, Sweden Tel +46730818201

Fax +462318375

Email catharina.gustavsson@Itdalarna.se 
pain-coping skills and self-management have shown to have a beneficial effect on pain-related disability. ${ }^{7-9}$ The rationale for self-management interventions is to induce health behavior changes that are assumed to produce sustainable long-term effects on disability. ${ }^{10}$ Pain self-management interventions aim to empower people to take control of their pain condition and thus reduce disability and improve quality of life outcomes. However, studies of treatment approaches involving components of self-management or self-care education specifically intended for people with neck pain are sparse, and there is no clear support for beneficial long-term effects on disability. ${ }^{11-14}$ The effectiveness of pain self-management interventions to enhance adherence to favorable coping skills, likewise to induce sustainable health behavior change, is sparsely investigated, and results on long-term maintenance of treatment gains are inconclusive. ${ }^{15-17}$

In previously reported short-term and long-term followups, a multicomponent pain and stress self-management group intervention (PASS) had better effect on pain control, pain-related self-efficacy for activities of daily living (ADL), disability and catastrophizing than a control treatment: individually administered physiotherapy (IAPT), for patients with persistent tension-type neck pain in PHC. ${ }^{18,19}$ Likewise, analysis showed that treatment gains, as measured by posttreatment scores at the 20-week follow-up, in disability, selfefficacy and pain intensity were associated with long-term outcome in pain-related disability at 2 years in patients with persistent neck pain participating in the PASS. ${ }^{20}$

When compared with the IAPT, a larger proportion of participants attending the PASS program reported that they used skills, which were gained during the intervention, to cope with pain in everyday life situations. The differences between the groups were less apparent at the 2-year followup, raising questions as to the sustainability of treatment effects, which warrants further investigation of the long-term effects of the intervention.

The objective of this study was to compare pain-related disability, self-efficacy for ADL, catastrophizing, pain, pain control, use of analgesics, and health care utilization in people with persistent tension-type neck pain 9 years after they received the PASS or IAPT.

\section{Materials and methods}

\section{Study design}

This study was a 9-year follow-up of a pragmatic ${ }^{21}$ randomized controlled trial ${ }^{22}$ evaluating the effects of a group-based pain self-management intervention as compared to IAPT in PHC.

\section{Study participants}

The inclusion criteria for this 9-year follow-up were as follows: all participants who had originally been included in the randomized controlled trial and who had not actively declined further participation at previous follow-ups. Of those 156 people (PASS, $n=77$; IAPT, $n=79$ ) originally included in the study, 129 people (PASS, $n=63$; IAPT, $\mathrm{n}=66$ ) were eligible for inclusion in the 9-year follow-up. The participants' current addresses were found by using the National Population Register.

\section{Study procedure}

In summary, patients with neck pain seeking physiotherapy treatment at nine PHC centers in eight towns in Sweden were consecutively recruited from September 2004 to April 2006. They were examined by a physiotherapist (PT) and considered eligible if they were 18-65 years of age and had tension-type neck pain of persistent duration, ie, $>3$ months. The reasons for exclusion were as follows: insufficient fluency in Swedish, medical history of psychotic disorder, pregnancy, ongoing treatment for neck pain, previously received PASS, or possible depression indicated by a score of $\geq 11$ points on the depression subscale of the Hospital Anxiety and Depression Scale (HADS-D). ${ }^{23}$ After completing the baseline self-assessment questionnaire, the participants were randomly allocated to either the experimental treatment PASS or the control treatment IAPT. The allocation sequence was prepared prior to the study with a random table, in randomly permuted blocks of two, four and eight, and stratified by the PHC center. An assistant who was not involved in delivering the interventions administered the opening of sealed opaque envelopes containing group allocation. PASS or IAPT treatment was delivered at the PHC center by experienced PTs. All participating PHC centers had at least three PTs employed. Each PT delivered only one of the interventions: PASS or IAPT. Prior to the study, the PTs delivering PASS attended a course that included the theories and the rationale behind the intervention, as well as detailed instructions and practical exercises from a manual of the eight PASS sessions. They were then provided with the manual and instructed to faithfully adhere to it. During the study, the PTs received performance feedback sessions. The other PTs working at the PHC centers provided IAPT in accordance with the current practice at their clinics.

Follow-ups were conducted 20 weeks, 1 year and 2 years after inclusion by using similar self-assessment questionnaires, which were mailed to the participants. In the present study, the same self-assessment questionnaire was mailed to 
the participants' home addresses together with an information letter and a form for informed consent. The participants who agreed to participate returned the questionnaire and the signed informed consent by mail. Two reminders were sent to the participants who did not respond to the first letter.

Detailed descriptions of design and methods have been reported in previous publications on posttreatment effects ${ }^{18}$ and 2-year follow-up of effects. ${ }^{19}$ The trial was approved by the ethics committee of Uppsala University (Ups 02-088), as was the 9-year follow-up (Ups 2013/345).

\section{Interventions}

PASS was a multicomponent group intervention consisting of seven weekly group sessions of 1.5 hours each and an additional booster session at 20 weeks after the initial session targeting the maintenance of coping skills. Each session consisted of applied relaxation training, body-awareness exercises and interactive lectures, emphasizing two-way communication and group discussions concerning issues related to pain self-management, according to a written manual. ${ }^{18}$ The applied relaxation ${ }^{24}$ comprised progressive and autogenic relaxation methods and conditioned relaxation exercises, eg, cue-controlled relaxation by thinking "relax" while exhaling. The rationale was to teach the patient active pain- and stress-coping skills by identifying personal "risk situations" in everyday life (ie, activities, movements or thoughts believed to cause pain or stress) and applying the relaxation techniques in these situations to manage physical arousal and thereby prevent the pain from starting or to control it. The body-awareness exercises ${ }^{25}$ were standing movement exercises that aimed to increase the awareness of oneself in the present moment, ie, the ability to sustain the attention on mental and bodily signals in nonevaluative, moment-tomoment awareness and to provide an opportunity to practice and apply relaxation when standing and during movement.

IAPT sessions were administered in accordance with the current practice and were not a standardized treatment procedure, in order to reflect the current practice at the participating PHC centers. The sessions involved several treatment modalities (spinal mobilization techniques and massage, acupuncture, transcutaneous electrical nerve stimulation and introduced the patient to individually tailored exercise programs (home-exercise programs, gym-based exercise programs, water-exercise programs). The type of treatment, frequency of visits and duration of contact were left to the judgment of and mutual agreement between the PT and the patient. The participants in the IAPT group were not to receive the PASS, but in no other way was treatment restricted.
The PASS participants attended an average of seven (range four to eight) group sessions, and the IAPT participants received an average of 11 (range 1-52) individual sessions over the 20 -week intervention period. Detailed descriptions of the contents of the experimental treatment PASS and the control treatment IAPT have previously been reported. ${ }^{18}$

\section{Data collection}

The self-assessment questionnaire used for this 9-year follow-up comprised questions on pain-related disability, self-efficacy for ADL, catastrophizing, pain intensity, perceived pain control, analgesics and health care utilization, as well as a question on the use of coping skills acquired during treatment and a question on satisfaction with care:

- Disability: Perceived interference with ADL due to neck pain was assessed using the Neck Disability Index (NDI) ${ }^{26,27}$ containing 10 Likert-type questions each with five response options. Summed responses were expressed as an index of $0-100$, where a higher value reflected more disability.

- Self-efficacy for performing ADL: This was assessed by the Self-Efficacy Scale (SES) ${ }^{28,29}$ The participants rated how confident they were that they could do 20 activities despite pain on an 11-point numeric rating scale $(0=$ not at all confident, $10=$ very confident).

- Catastrophizing: The propensity to engage in negative thinking and worry in response to pain was assessed by the Coping Strategies Questionnaire - catastrophizing subscale (CSQ-CAT), ${ }^{30-32}$ entailing six items with response options by numeric rating scales rating from $0=$ never to $6=$ always.

- Pain intensity: This was measured by three variables, ie, "at present", "on average the previous week" and "at worst the previous week", with response options by numeric rating scales ranging from $0=$ no pain to $10=$ worst possible pain. ${ }^{33}$

- Pain control: This was measured by the two questions from the CSQ, ${ }^{30,31}$ assessing the overall effectiveness of coping strategies. Participants rated the extent to which they were able to control or reduce pain $(0=$ no control/cannot reduce, $6=$ complete control/can reduce completely).

- Use of analgesics: Usage of analgesics for neck pain was measured by a 5-point Likert-type scale reflecting frequency, with the following response options: "every day", "every second day", "about 1 or 2 days per week", "about 1 or 2 days per month" and "never". 
- Health care utilization: Information on the number of health care visits due to neck pain during the preceding 3 months and on the number of days on sick leave due to neck pain during the preceding 3 months was collected by self-report in the questionnaire.

- Satisfaction with care (allocated treatment): This was assessed by the question "How satisfied are you with the care that you received during the intervention period?", measured by a 5-point Likert-type scale, with response options from "very content/satisfied" to "very discontent/ dissatisfied".

- Use of skills acquired during the intervention to cope with pain: This was assessed by the question "Can you use/apply things you learned during the intervention in everyday life situations to cope with pain?", measured by a 5-point Likert-type scale reflecting frequency, with response options "every day", “often", "sometimes", "seldom" and "never".

\section{Statistical analyses}

The number of participants included in the original study was based on power calculations of the primary outcome variables "disability" and "self-efficacy", and it was estimated that a sample size of 150 would be sufficient to detect a $10 \%$ difference between groups (allowing for an estimated withdrawal of $30 \%$, power $0.80, p=0.05)$. However, the power calculations did not accommodate for a long-term follow-up. ${ }^{34,35}$

The primary analysis was simple main effects at 9 years. Mixed linear models for repeated measures analysis ${ }^{36}$ were conducted for the primary outcome variables disability and self-efficacy and for the secondary outcome variables. "Time" and "group" were fixed effects in the analyses and participants the random effect. The interaction term time by group was included in the model to evaluate the interaction effect of differences between groups at each follow-up and within-group differences over time. The analyses were based on five time points of assessment (ie, baseline, 20-week, 1-year, 2-year and 9-year follow-ups). The baseline value of the dependent variable was included in the outcome vector. The Schwarz's Bayesian Information Criterion suggested that an unstructured covariance structure yielded the best fit in all mixed model analyses. The ordinal responses were analyzed by fitting a generalized estimating equation (GEE) model with the GENMOD procedure in $\mathrm{SAS}^{\circledR}$ 9.3. The GEE strategy is a useful approach for repeated measurements analysis of ordered categorical outcomes. The model was set up with the same factors as in the mixed linear model mentioned earlier. The correlation structure used in the analyses was "independent", and the link function was "cumulative logit". The parameter estimates from the GEE model were presented as odds ratio and $95 \%$ confidence interval. Pairwise comparisons of simple main effects based on the mixed models were conducted to investigate differences between groups at the 9-year follow-up.

The chi-square test was applied for analyses of betweengroup differences at the 9-year follow-up on questions regarding "satisfaction with care" and "use of acquired skills in everyday life".

A $p$-value $\leq 0.05$ was accepted as statistically significant. Analyses were conducted using SAS 9.3 for mixed linear models and GEE analyses. IBM SPSS Statistics 21 for Windows was used for chi-square test (differences between groups on questions regarding "satisfaction with care" and "use of coping skills") and for calculating differences between responders and nonresponders.

Data analyses were based on participants with available data at the 9-year follow-up, and their data from all previous follow-ups were analyzed according to group allocation at baseline. Occasional single missing items in the instruments SES and CSQ-CAT were substituted with the median of the participant's responses to the other items included in the sum score on the same instrument. ${ }^{37}$ This was done for five participants on SES at 9-year follow-up, for two participants on SES at 2-year follow-up and for one participant on SES and one participant on CSQ-CAT at 1-year follow-up. That is, it was done in $<4 \%$ of the cases at 9 years and even less at previous follow-ups.

\section{Results}

Eighty percent of those originally included in the randomized controlled trial were eligible and approached for the 9-year follow-up. The remaining participants were not approached due to either that they had declined further participation at a previous follow-up $(n=24)$ or that they were deceased $(\mathrm{n}=3)$. Ninety-four people $(73 \%)$ responded to the 9 -year follow-up by returning the questionnaire (PASS, $\mathrm{n}=48$; IAPT, $\mathrm{n}=46$ ). The remaining 35 participants did not respond to the mailed invitation. Figure 1 provides a flow chart illustrating participation in the study over the follow-ups.

The baseline characteristics of the participants are displayed in Table 1, separately for all originally included participants and for responders to the 9-year follow-up. Baseline assessments are displayed in Table 2, likewise separately for all originally included participants and for responders to the 9 -year follow-up. Responders to the 9-year follow-up in the 


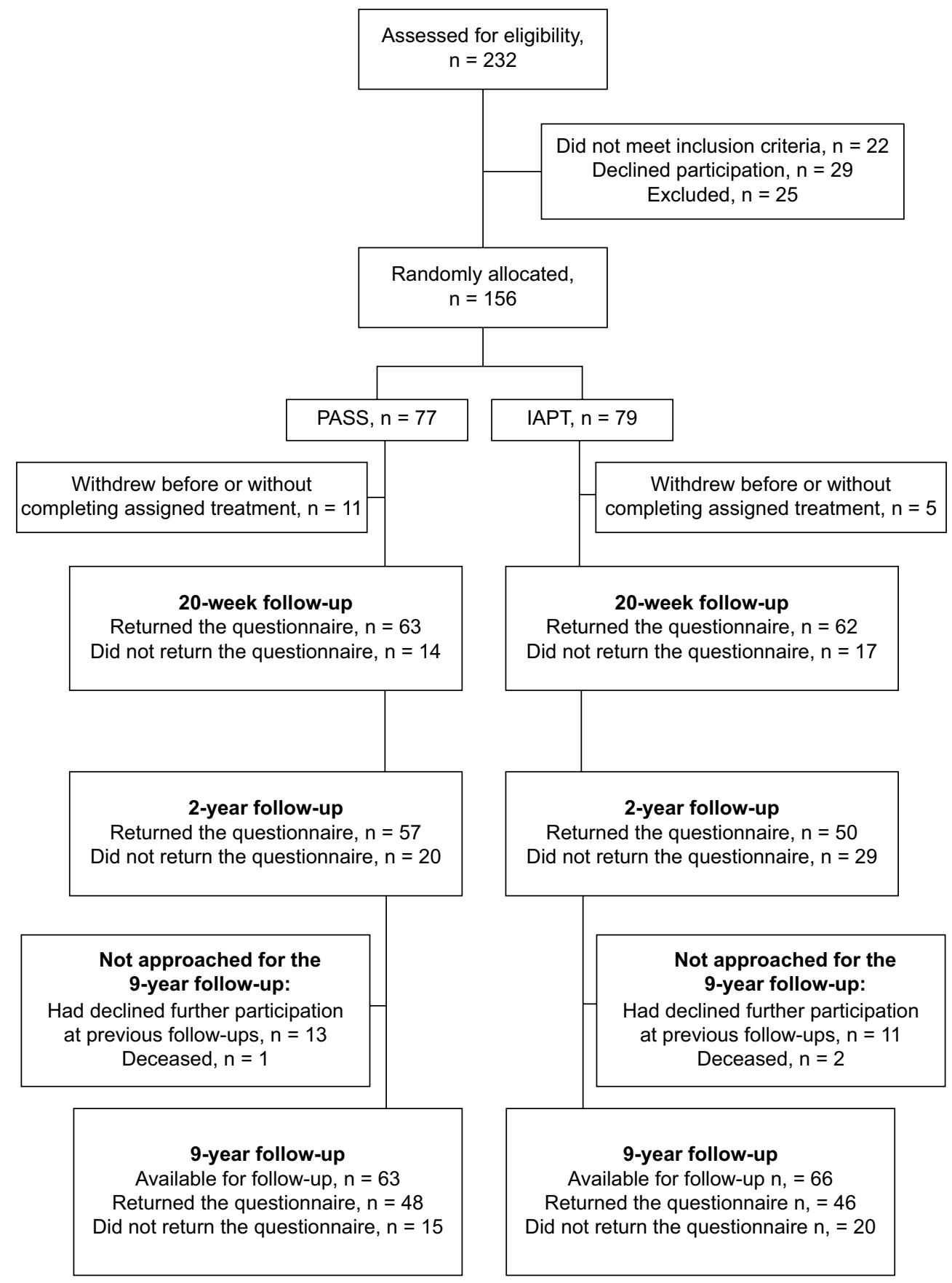

Figure I A flowchart illustrating participation in the study over the follow-ups.

Abbreviations: PASS, pain and stress self-management group intervention; IAPT, individually administered physiotherapy.

PASS group did not differ from all originally included PASS participants at baseline, nor to nonresponders to the 9-year follow-up. At baseline, responders in the IAPT group rated better self-efficacy for ADL as measured by SES ( $p=0.024)$ compared to all originally included participants in IAPT and nonresponders to the 9-year follow-up.

The results on outcome measures at 9 years are reported in Table 2. Mixed linear models and GEE analyses showed that there was an interaction "time by group" effect for disability, self-efficacy, catastrophizing, ability to pain control pain and number of health care visits due to neck pain. Analyses of simple main effects, ie, between-group comparison at the 9-year follow-up for variables with significant interaction effect, showed that there was a between-group difference at 9 years for disability $(p=0.006)$ and a trend for self-efficacy $(p=0.059)$ in favor of PASS. There were no significant differences between groups at 9 years regarding the other secondary outcome measures. 
Table I Baseline characteristics for PASS group and IAPT group

\begin{tabular}{|c|c|c|c|c|}
\hline & \multicolumn{2}{|c|}{ All participants originally included } & \multicolumn{2}{|c|}{ Responders at 9-year follow-up } \\
\hline & PASS group & IAPT group & PASS group & IAPT group \\
\hline & $\mathrm{n}=\mathbf{7 7}$ & $\mathbf{n}=\mathbf{7 9}$ & $n=48$ & $n=46$ \\
\hline Female/male, n (\%)/n (\%) & $69(90) / 8(10)$ & $70(89) / 9(1 \mathrm{I})$ & $45(94) / 3(6)$ & $43(93) / 3(7)$ \\
\hline Age, mean (SD), range & 45.7 (II.5), 19-65 & 45.7 (II.6), 20-63 & 47 (10.6), 19-64 & 46.2 (II), 20-62 \\
\hline \multicolumn{5}{|l|}{ Pain intensity, mean (SD) } \\
\hline Present $(0-10)$ & $5.5(2)$ & $5.9(2)$ & $5.5(1.9)$ & $6(2.1)$ \\
\hline Average $(0-10)$ & $6(1.8)$ & $6.4(2)$ & $6.2(1.8)$ & $6.4(2)$ \\
\hline Worst/maximum (0-10) & $8.4(1.4)$ & $8.5(1.2)$ & $8.4(1.3)$ & $8.6(1.1)$ \\
\hline \multicolumn{5}{|l|}{ Duration of neck pain, $\mathrm{n}(\%)$} \\
\hline $3-6$ months & 7 (9) & $11(14)$ & $3(6.3)$ & $6(13)$ \\
\hline $7-12$ months & $4(5)$ & $9(I I)$ & $4(8.3)$ & $7(15.2)$ \\
\hline $1-2$ years & $12(16)$ & $12(15)$ & $6(12.5)$ & $8(17.4)$ \\
\hline$>2$ years & $54(70)$ & $47(60)$ & $35(72.9)$ & $25(54.3)$ \\
\hline \multicolumn{5}{|l|}{ Use of analgesics due to neck pain, $n(\%)$} \\
\hline Never & $12(16)$ & $12(15)$ & $8(16.7)$ & $8(17.4)$ \\
\hline I or 2 days per month & $28(36)$ & $19(24)$ & $16(33.3)$ & $7(15.2)$ \\
\hline I or 2 days per week & $18(23)$ & $20(25)$ & $14(29.2)$ & $10(21.7)$ \\
\hline Every second day & $9(12)$ & II (14) & $4(8.3)$ & $9(19.6)$ \\
\hline Everyday & $10(13)$ & $17(22)$ & $6(12.5)$ & $12(26.1)$ \\
\hline \multicolumn{5}{|l|}{ Current level of sick leave, $n(\%)$} \\
\hline Not on sick leave & $52(67)$ & $39(49)$ & $31(64.6)$ & $22(47.8)$ \\
\hline $25 \%$ sick leave & $3(4)$ & $6(8)$ & $2(4.2)$ & $4(8.7)$ \\
\hline $50 \%$ sick leave & $9(12)$ & 7 (9) & $8(16.7)$ & $6(13)$ \\
\hline $75 \%$ sick leave & $3(4)$ & $2(2)$ & $2(4.2)$ & $\mathrm{I}(2.2)$ \\
\hline Totally off work/sick leave & $10(13)$ & $25(32)$ & $5(10.4)$ & $13(28.3)$ \\
\hline Days of sick leave during preceding 3 months (0-90), mean (SD) & $22(35.2)$ & $32.9(40.8)$ & $23.9(35.5)$ & $38.6(41.7)$ \\
\hline Health care visits due to pain during preceding 3 months, mean (SD) & $2.4(3.2)$ & $2.8(3.5)$ & $2.5(2.8)$ & $2.7(3.2)$ \\
\hline NDI score (0-100), mean (SD) & $30.8(10.7)$ & $35.4(14)$ & $31.5(11.7)$ & $34.3(14.6)$ \\
\hline SES score (0-200), mean (SD) & $136.7(39.8)$ & $128.3(43.5)$ & $136(44)$ & $136.8(42.2)$ \\
\hline CSQ pain control (0-6), mean (SD) & $3.3(1.1)$ & $3.1(1.2)$ & $3.4(1.2)$ & $3.2(1.1)$ \\
\hline CSQ ability to reduce pain (0-6), mean (SD) & $2.9(1)$ & $2.9(0.9)$ & $2.9(1.2)$ & $2.8(0.8)$ \\
\hline CSQ-CAT score (0-36), mean (SD) & $11.3(7.4)$ & $11.8(7.1)$ & $11.9(7.9)$ & $12(7.3)$ \\
\hline HADS-D score $(0-2 \mathrm{I})$, mean (SD) & $4.3(3.1)$ & $4.9(8.9)$ & $4.6(3.2)$ & $4.9(3)$ \\
\hline HADS-A score (0-2I), mean (SD) & $8.2(4.1)$ & $8.1(3.9)$ & $8.3(4.2)$ & $7.6(3.2)$ \\
\hline
\end{tabular}

Abbreviations: PASS, pain and stress self-management group intervention; IAPT, individually administered physiotherapy; NDI, Neck Disability Index; SES, Self-Efficacy Scale; CSQ, Coping Strategies Questionnaire; CSQ-CAT, Coping Strategies Questionnaire - catastrophizing subscale; HADS-D, depression subscale of the Hospital Anxiety and Depression Scale; HADS-A, anxiety subscale of the Hospital Anxiety and Depression Scale.

Between-group comparisons for categorical data are presented in Table 3. At 9 years, there were no longer differences between the groups with regard to the questions on "satisfaction with care" or "use of coping skills acquired during the intervention", as previously seen at 1 year and 2 years. There was a trend that the PASS group reported that during treatment they had learned useful skills, which they could apply in everyday life to cope with pain, to a higher degree than the IAPT group $(p=0.061)$.

The self-reported number of days on sick leave due to neck pain during the preceding 3 months was similar in both groups both at baseline and at the 9-year follow-up. An analysis of those participants who were $\leq 56$ years old at inclusion to the study (PASS, $\mathrm{n}=62$; IAPT, $\mathrm{n}=62$ ) showed that half of the participants in each group had no preceding sick leave due to neck pain at baseline and $16 \%$ in the PASS group and $25 \%$ in the IAPT group had 90 days of sick leave during the 3 months preceding baseline. At the 9-year followup, half of the participants in each group had no sick leave during the preceding 3 months and two people in the PASS group and three people in the IAPT group had 90 days of sick leave during the preceding 3 months, ie, were completely on sick leave.

\section{Discussion}

To the best of our knowledge, this is the first extended longterm follow-up of the treatment effects of a self-management intervention for people with persistent tension-type neck pain. Indeed, at this 9-year follow-up, a difference in disability in favor of PASS and a trend for better self-efficacy for ADL were still present. There were also between-group differences at 9 years in favor of PASS in terms of one aspect 
Table 2 Between- and within-group comparisons for PASS and IAPT

\begin{tabular}{|c|c|c|c|c|c|c|c|c|}
\hline \multirow{4}{*}{$\begin{array}{l}\text { Outcome measure } \\
\text { treatment group }\end{array}$} & \multirow{4}{*}{$\begin{array}{l}\text { Baseline } \\
\text { assessment } \\
\left(n=129^{a}\right) \\
\text { Mean (SD) }\end{array}$} & \multirow{4}{*}{$\begin{array}{l}\text { 9-year } \\
\text { follow-up } \\
\left(n=94^{b}\right) \\
\text { Mean (SD) }\end{array}$} & \multirow{2}{*}{\multicolumn{3}{|c|}{$\begin{array}{l}\text { Mixed linear models comparisons } s^{\mathrm{c}, \mathrm{d}} \\
\text { Baseline-9-year follow-up } \\
\left(\mathrm{n}=129^{\mathrm{a}}\right)\end{array}$}} & \multirow{2}{*}{\multicolumn{3}{|c|}{$\begin{array}{l}\text { Simple main effects } \\
\text { Between-group comparison at } \\
9 \text { years }\left(n=129^{a}\right)\end{array}$}} \\
\hline & & & & & & & & \\
\hline & & & \multirow{2}{*}{$\begin{array}{l}\text { Group } \\
p \text {-value }\end{array}$} & \multirow{2}{*}{$\begin{array}{l}\text { Time } \\
p \text {-value } \\
\end{array}$} & \multirow{2}{*}{$\begin{array}{l}\text { Time } \times \text { group } \\
p \text {-value }\end{array}$} & \multirow[t]{2}{*}{ Estimate } & \multirow[t]{2}{*}{$95 \% \mathrm{Cl}$} & \multirow[t]{2}{*}{$p$-value } \\
\hline & & & & & & & & \\
\hline NDI score $(0-100)$ & & & 0.0002 & $<0.0001$ & 0.016 & -8.4 & -14.33 to -2.46 & 0.006 \\
\hline PASS group & $30.5(11.2)$ & $19(15.9)$ & & & & & & \\
\hline IAPT group & $35.6(13.9)$ & $26(16.8)$ & & & & & & \\
\hline SES score (0-200) & & & 0.002 & $<0.0001$ & 0.012 & 14.5 & -0.58 to 29.58 & 0.059 \\
\hline PASS group & | 38.5 (40.6) & $168.5(37.7)$ & & & & & & \\
\hline IAPT group & $129.4(42.2)$ & $157(43)$ & & & & & & \\
\hline Pain at present $(0-10)$ & & & 0.003 & $<0.0001$ & 0.383 & -0.79 & -1.83 to 0.24 & 0.132 \\
\hline PASS group & $5.5(2)$ & $3.2(2.5)$ & & & & & & \\
\hline IAPT group & $6.1(2)$ & $3.9(2.9)$ & & & & & & \\
\hline Pain average $(0-10)$ & & & 0.004 & $<0.0001$ & 0.700 & -1.0 & -2.06 to 0.07 & 0.068 \\
\hline PASS group & $6.1(1.9)$ & $3.4(2.6)$ & & & & & & \\
\hline IAPT group & $6.6(2)$ & $4.2(2.9)$ & & & & & & \\
\hline Pain worst/maximum $(0-10)$ & & & 0.011 & $<0.0001$ & 0.080 & -1.4 & -2.59 to -0.13 & 0.031 \\
\hline PASS group & $8.4(1.4)$ & $5.4(3.2)$ & & & & & & \\
\hline IAPT group & $8.6(1.2)$ & $6.6(3.1)$ & & & & & & \\
\hline CSQ-CAT score $(0-36)$ & & & 0.001 & $<0.0001$ & $<0.0001$ & -1.3 & -4.01 to -1.37 & 0.334 \\
\hline PASS group & II.4 (7.5) & $6.6(6.7)$ & & & & & & \\
\hline IAPT group & $12.3(7.0)$ & $7(7.2)$ & & & & & & \\
\hline $\begin{array}{l}\text { Health care visits due to neck pain } \\
\text { during preceding } 3 \text { months }\end{array}$ & & & 0.018 & 0.0006 & $<0.0001$ & -0.2 & -0.53 to 0.11 & 0.197 \\
\hline PASS group & $2.3(3.6)$ & $1.6(2.1)$ & & & & & & \\
\hline \multirow[t]{4}{*}{ IAPT group } & $2.6(3.1)$ & $2.9(5.1)$ & & & & & & \\
\hline & Md (IQR) & Md (IQR) & \multicolumn{3}{|c|}{ GEE models comparisons ${ }^{d}$} & OR & $95 \% \mathrm{Cl}$ & $p$-value \\
\hline & & & Group & Time & Time $\times$ group & & & \\
\hline & & & $p$-value & $p$-value & $p$-value & & & \\
\hline CSQ ability to control pain (0-6) & & & 0.0006 & $<0.0001$ & $<0.0001$ & 0.93 & $0.42-2.06$ & 0.865 \\
\hline PASS group & $3(3-4)$ & $4(3-5)$ & & & & & & \\
\hline IAPT group & $3(3-4)$ & $4(3-5)$ & & & & & & \\
\hline CSQ ability to reduce pain $(0-6)$ & & & 0.002 & $<0.0001$ & 0.129 & 1.44 & $0.64-3.25$ & 0.378 \\
\hline PASS group & $3(3-3)$ & $4(3-5)$ & & & & & & \\
\hline IAPT group & $3(3-3)$ & $3(3-4)$ & & & & & & \\
\hline $\begin{array}{l}\text { Use of analgesics due to neck } \\
\text { pain }(0-4)\end{array}$ & & & 0.003 & $<0.0001$ & 0.423 & 2.25 & $1.05-4.81$ & 0.027 \\
\hline PASS group & $\mathrm{I}(\mathrm{I}-2.5)$ & $I(0-I)$ & & & & & & \\
\hline IAPT group & $2(I-3)$ & $\mathrm{I}(0.5-2.5)$ & & & & & & \\
\hline
\end{tabular}

Notes: Comparisons based on all available data at 9-year follow-up, ie, baseline values for the participants available and approached for the 9-year follow-up (PASS group,

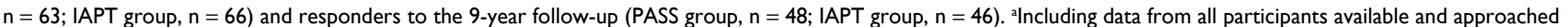
for 9-year follow-up, ie, PASS, $n=63$, and IAPT, $n=66$. 'Including data from responders to the 9-year follow-up, ie, PASS, $n=48$, and IAPT, $n=46$. ${ }^{c}$ Covariance structure used for mixed model analyses: unstructured. ${ }^{\mathrm{d}}$ Analyses based on five time points of assessment (ie, baseline, 20-week, I-year, 2-year and 9-year follow-up). Differences with a significance level of $p \leq 0.05$ are indicated in bold.

Abbreviations: PASS, pain and stress self-management group intervention; IAPT, individually administered physiotherapy; Cl, confidence interval; NDI, Neck Disability Index; SES, Self-Efficacy Scale; CSQ-CAT, Coping Strategies Questionnaire - catastrophizing subscale; GEE, generalized estimating equation; Md, median; IQR, interquartile range; OR, odds ratio; CSQ, Coping Strategies Questionnaire.

of pain and use of analgesics due to neck pain. Our findings indicate that this self-management group intervention appears to render sustainable favorable effects on disability.

It is an important finding that there was still a difference between the groups in disability with regard to ADL as measured by NDI. Previous research on self-management programs for chronic pain conditions has failed to provide convincing evidence for long-term effects on disability. ${ }^{12,16}$
Our finding that PASS reduced neck disability resonates with the primary objective of self-management interventions: to impact the consequences of illness, ie, disability, rather than to reduce symptoms, in this case pain. ${ }^{10}$ Learning to self-manage pain is a key to attaining favorable paincoping skills and thereby regaining control over one's life, rather than letting pain control one's life. ${ }^{38,39}$ Regaining control can be the first step toward reduction in perceived 


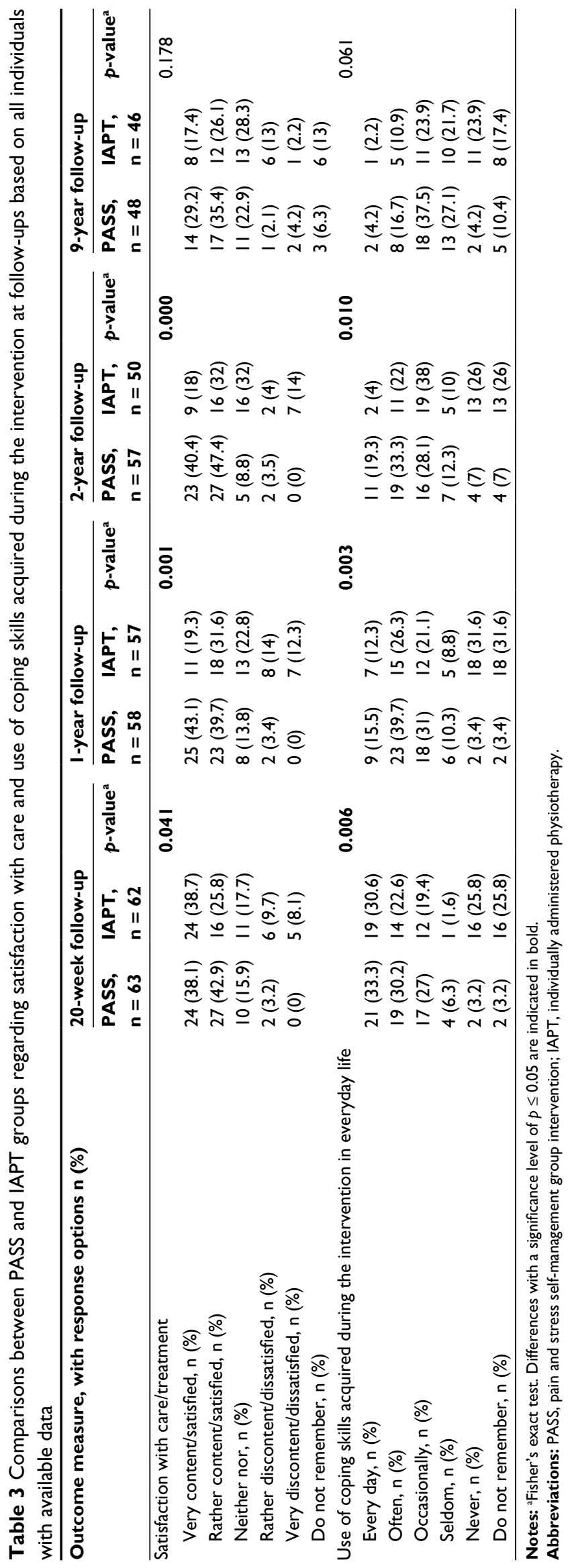

pain interference. ${ }^{8,40}$ Likewise, it has been suggested that interventions toward persistent nonmalignant pain conditions should first and foremost target the reduction in the pain-related disability rather than the pain intensity. ${ }^{8,41}$

There was a difference between groups only with regard to one of the three pain measures: "pain at worst". Our results may indicate that differences in disability were not dependent on differences in pain-intensity measures. This is in line with research showing weak correlations between pain intensity and disability. ${ }^{1,42,43}$ Also, a previous research has suggested that rather ability to control pain and coping may contribute to less disability. ${ }^{35}$ In the light of the latter, the difference between groups with regard to "pain at worst" in favor of PASS at 9 years is worthy of note and important to discuss. It could be argued that the difference in perceived "pain at worst" might reflect a shift in perception, ie, change in the cognitive and affective processing in the brain, of when pain becomes intolerable/uncontrollable, ${ }^{44}$ and is thus an indication of better perceived control over pain. Experimental studies have shown that when given the possibility to execute personal control over an experimentally induced painful procedure, the experience of pain intensity and unpleasantness is reduced ${ }^{44-46} \mathrm{In}$ addition, the results on the pain measure "pain at worst" and the measure of analgesics consumption "use of analgesics due to neck pain" strengthen each other by pointing in the same direction, ie, the PASS participants perceived less pain at worst and had a lower frequency of use of analgesics. A shift in coping strategies is another possible explanation for the difference between the groups in frequency of taking analgesics due to neck pain. In the population of people with tension-type neck pain, taking medication has been suggested to be a passive coping strategy. ${ }^{7,47}$

The self-management intervention aimed to reinforce active coping strategies, such as applying relaxation and body-awareness techniques, ie, physically and mentally tension-reducing techniques, in self-identified risk situations. It is plausible that the PASS group used such active coping strategies instead of taking pain medication. On the other hand, the result on the question "use of coping skills acquired during the intervention" may just point in the opposite direction: it showed that there was no longer a difference between groups as previously seen at 1 year and 2 years (although a possible trend [ $p=0.061]$ in favor of PASS). However, it could also indicate that the PASS participants had integrated their skills to the extent that the coping strategies were no longer perceived as conscious thoughts and actions but instead as habitual behaviors in the person's everyday life. If so, it is 
conceivable that an actual and profound behavior change had taken place. A somewhat similar suggestion could be applied to a 3-year follow-up of a physical activity intervention in which treatment effects were largely maintained, although adherence to the specific home training program faltered considerably. ${ }^{48}$ This raises the question of whether coping skills gradually become integrated behaviors in ordinary life and if they become, then they are no longer perceived to be intentional actions or specific exercises. However, the present study was not designed to address this research question. Such an assumption could not be confirmed by the methods for data collection and results of this study. Exploration of such experiences needs to be further investigated in future studies. In addition, one should bear in mind the obvious risk of memory bias ${ }^{49}$ when asking people about things that happened several years ago. It is unarguably very difficult to remember what was learned during an intervention that took place 9 years ago. Likewise, responses to the question regarding "satisfaction with care" were possibly subject to memory bias. There was no longer a difference between the groups regarding "satisfaction with care", as was previously seen at 1 year and 2 years.

Work-related disability as measured by self-reported days on sick leave due to neck pain was similar and low in both groups at both baseline and at the 9-year follow-up. Half of the participants ( $\leq 56$ years old) in each group had no sick leave days during the 3 months preceding baseline and $16 \%$ in the PASS group and $25 \%$ in the IAPT group had 90 days of sick leave during the 3 months preceding baseline. At the 9-year follow-up, very few participants in either group (PASS, $n=2$; IAPT, $\mathrm{n}=3$ ) had long-term sick leave, ie, had 90 days of sick leave due to neck pain during the preceding 3 months. The low number of days on sick leave might reflect a difference in the population of people with neck pain, as compared to other populations with pain, for example, people with low back pain, where work-related disability is much more common and the number of days of sick leave is often larger. ${ }^{4,50}$

It has been suggested that self-efficacy for ADL despite pain is important to target in pain self-management interventions to achieve favorable health outcomes. ${ }^{10,39}$ Self-efficacy is a key factor for ability to adopt and also maintain selfmanagement behavior. ${ }^{39,51}$ There is strong evidence suggesting that self-efficacy is an important mediator between pain and disability ${ }^{29,52,53}$ and that targeting self-efficacy in pain self-management programs is associated with reduction in disability ${ }^{20,54,55}$ and beneficial for other health outcomes. ${ }^{15,19}$ The concept of self-efficacy, according to the social cognitive theory, ${ }^{56}$ was an important theoretical basis for the PASS. The concept emphasizes how self-efficacy beliefs are influenced by personal experiences of accomplishment, ie, "mastery experiences", social reinforcements and social modeling, ie, "vicarious" experiences by observing others and verbal persuasion and the affective state within the individual. All these factors were addressed in PASS by the application of coping skills in ADL to reinforce personal mastery experiences and techniques for dealing with fear or other aversive emotional arousal that could impede performance. ${ }^{57}$ The intervention was offered in a group setting with ample opportunities for social reinforcement through the observation of others and the receiving of feedback on accomplishments from the therapist and fellow group participants. At the 9-year follow-up, there was no difference between the groups, but there was a trend that the PASS group had better self-efficacy for ADL. In this 9-year follow-up, the participants in the IAPT group had better self-efficacy at baseline than all participants originally included in the IAPT. By having participants in the IAPT group who differed by baseline self-efficacy compared to the original IAPT participants, we might have diminished existing differences between the groups at the 9-year follow-up.

For self-management interventions to be perceived as beneficial with regard to producing sustainable behavior change, the effects need to be maintained over time. We believe that there are several important reasons for the beneficial long-term effects of PASS: 1) the design of the program, ie, the theoretical base grounded in social cognitive theory and especially targeting the enhancement of self-efficacy beliefs for active pain self-management, ${ }^{58}$ and likewise the use of behavior-change techniques to promote health behavior change toward active coping skills; ${ }^{59,60} 2$ ) using a combination of treatment components (not relying on one single component), ie, applied relaxation, ${ }^{24}$ bodyawareness exercises ${ }^{25}$ and interactive group discussions that targeted pain education ${ }^{61}$ and enhancing personalized plans, goal setting and problem-solving skills; ${ }^{10,59}$ and 3) foremostly, the format and administration of the program, ie, the focus on applying ${ }^{60}$ everything that was targeted during sessions (ie, self-management skills, personalized plans and goal setting, problem-solving skills), in-between sessions through homework assignments and subsequently at the next session receiving feedback on homework assignments and support from the health care provider and the peers in the group.

The PASS entailed only seven weekly administered group sessions and one booster session 3 months later. Studies have suggested that in interventions that require active patient participation and readiness to adopt new behaviors, it is important to include repeated checkups on adherence and/or 
a considerable amount of maintenance supporting behavioral techniques in order to produce sustainable treatment effects. ${ }^{48,62,63}$ Other pain self-management group interventions have included more extensive maintenance components to reinforce the class sessions, for example, additional individual sessions ${ }^{64}$ or telephone calls ${ }^{55}$ monthly over a year, or follow-up group sessions after the main program. ${ }^{63}$ The PASS intervention entailed only one additional booster session at 20 weeks after the initial session that exclusively targeted the maintenance of coping skills. However, the preceding seven weekly group sessions were thoroughly designed to induce sustainability by applying evidence-based behaviorchange techniques: ${ }^{59}$ ie, the application of relaxation and body-awareness exercises through homework assignments and self-monitoring in personally identified risk situations for pain flare-ups and likewise, receiving performance feedback on homework assignments and encouragement to apply problem-solving techniques to progressively refine the practice. With this procedure, coping skills were supposed to profoundly affect both bodily and cognitive dimensions of the individual. After the seventh session, participants were supposed to be well acquainted and prepared to independently use the coping strategies and to apply problem-solving skills as needed. The results of this study suggest that the treatment procedure, ie, the number of sessions and distribution over time, of the PASS intervention was sufficient to produce a sustainable behavior change and reduce disability, thus indicating that key components for the enhancement of long-term effectiveness in self-management behaviors were sufficiently targeted in the intervention and support the assumptions and rationale for this pain self-management program. However, it could not be ruled out that additional sessions with checkups of adherence to self-management strategies could have produced even more exhaustive treatment gains.

A strength of the study is that comparison of simple main effects for the 9-year follow-up based on mixed linear models and GEE analyses enabled accommodating for differences over time and by group. Another strength of this study is that the responders to this 9-year follow-up did not differ with regard to baseline characteristics/measures; this was the case with both all originally included participants and those who were eligible and approached for this follow-up, with the exception that responders in IAPT had better self-efficacy than all the participants included in IAPT. However, the vast majority of participants were women, which limits the generalizability of the results. The results could not be generalized to men.

A limitation of the study is that that all participants eligible for this 9-year follow-up did not respond despite reminders. Responses to the 9-year follow-up were obtained from $73 \%$ of those eligible at 9 years, corresponding to $60 \%$ of the original number of participants in the randomized controlled trial. Thus, the number of participants was acceptable but limited the capacity to ensure power to detect important differences. It is possible that we failed to detect differences in treatment effects that were present.

\section{Acknowledgments}

The authors thank the statistician Elisabeth Berg (Karolinska Institutet, Stockholm) for statistical advice. The study was funded by grants from the Center for Clinical Research Dalarna and Karolinska Institutet.

\section{Author contributions}

Both authors have substantially contributed to all parts of the study: the study design, acquisition and analysis of data, interpretation of results, and drafting of the manuscript. Both authors have approved the final version of the manuscript and are accountable for all aspects of the work.

\section{Disclosure}

The authors report no conflicts of interest in this work.

\section{References}

1. Hogg-Johnson S, van der Velde G, Carroll LJ, et al; Bone and Joint Decade 2000-2010 Task Force on Neck Pain and Its Associated Disorders. The burden and determinants of neck pain in the general population: results of the bone and joint decade 2000-2010 task force on neck pain and its associated disorders. Spine. 2008;33(4 Suppl): S39-S51.

2. Guez M, Hildingsson C, Nilsson M, Toolanen G. The prevalence of neck pain: a population-based study from northern Sweden. Acta Orthop Scand. 2002;73(4):455-459.

3. Hill J, Lewis M, Papageorgiou AC, Dziedzic K, Croft P. Predicting persistent neck pain: a 1-year follow-up of a population cohort. Spine. 2004;29(15):1648-1654.

4. Enthoven P, Skargren E, Oberg B. Clinical course in patients seeking primary care for back or neck pain: a prospective 5-year follow-up of outcome and health care consumption with subgroup analysis. Spine. 2004;29(21):2458-2465.

5. Linton SJ, Andersson T. Can chronic disability be prevented? A randomized trial of a cognitive-behavior intervention and two forms of information for patients with spinal pain. Spine. 2000;25(21):2825-2831.

6. Green AJ, Jackson DA, Klaber Moffett JA. An observational study of physiotherapists' use of cognitive-behavioural principles in the management of patients with back pain and neck pain. Physiotherapy. 2008;94:306-313.

7. Blyth FM, March LM, Nicholas MK, Cousins MJ. Self-management of chronic pain: a population-based study. Pain. 2005;113(3):285-292.

8. Turk DC, Swanson KS, Tunks ER. Psychological approaches in the treatment of chronic pain patients - when pills, scalpels, and needles are not enough. Can J Psychiatry. 2008;53(4):213-223.

9. Smeets RJ, Vlaeyen JW, Hidding A, et al. Active rehabilitation for chronic low back pain: cognitive-behavioral, physical, or both? First direct post-treatment results from a randomized controlled trial [ISRCTN22714229]. BMC Musculoskelet Disord. 2006;7:5. 
10. Lorig KR, Holman H. Self-management education: history, definition, outcomes, and mechanisms. Ann Behav Med. 2003;26(1):1-7.

11. Hurwitz EL, Carragee EJ, van der Velde G, et al; Bone and Joint Decade 2000-2010 Task Force on Neck Pain and Its Associated Disorders. Treatment of neck pain: noninvasive interventions: results of the bone and joint decade 2000-2010 task force on neck pain and its associated disorders. Spine. 2008;33(4 Suppl):S123-S152.

12. Du S, Yuan C, Xiao X, Chu J, Qiu Y, Qian H. Self-management programs for chronic musculoskeletal pain conditions: a systematic review and meta-analysis. Patient Educ Couns. 2011;85(3):e299-e310.

13. Gross AR, Kaplan F, Huang S, et al. Psychological care, patient education, orthotics, ergonomics and prevention strategies for neck pain: an systematic overview update as part of the ICON Project. Open Orthop J. 2013;7:530-561.

14. Leaver AM, Refshauge KM, Maher CG, McAuley JH. Conservative interventions provide short-term relief for non-specific neck pain: a systematic review. J Physiother. 2010;56(2):73-85.

15. Damush TM, Kroenke K, Bair MJ, et al. Pain self-management training increases self-efficacy, self-management behaviours and pain and depression outcomes. Eur J Pain. 2016;20(7):1070-1078.

16. Oliveira VC, Ferreira PH, Maher CG, Pinto RZ, Refshauge KM, Ferreira ML. Effectiveness of self-management of low back pain: systematic review with meta-analysis. Arthritis Care Res (Hoboken) 2012;64(11):1739-1748.

17. Boyers D, McNamee P, Clarke A, et al. Cost-effectiveness of selfmanagement methods for the treatment of chronic pain in an aging adult population: a systematic review of the literature. Clin J Pain. 2013; 29(4):366-375.

18. Gustavsson C, Denison E, Koch L. Self-management of persistent neck pain: a randomized controlled trial of a multi-component group intervention in primary health care. Eur J Pain. 2010;14(6): 630.e1-630.e11.

19. Gustavsson C, Denison E, von Koch L. Self-management of persistent neck pain: two-year follow-up of a randomized controlled trial of a multicomponent group intervention in primary health care. Spine (Phila Pa 1976). 2011;36(25):2105-2115.

20. Gustavsson C, Bergstrom J, Denison E, von Koch L. Predictive factors for disability outcome at twenty weeks and two years following a pain self-management group intervention in patients with persistent neck pain in primary health care. $J$ Rehabil Med. 2013;45(2): $170-176$

21. Jadad A. Randomised Controlled Trials. A User's Guide. London: BMJ Books; 1998.

22. Boutron I, Moher D, Altman DG, Schulz KF, Ravaud P; CONSORT Group. Extending the CONSORT statement to randomized trials of nonpharmacologic treatment: explanation and elaboration. Ann Intern Med. 2008;148(4):295-309.

23. Zigmond AS, Snaith RP. The Hospital Anxiety and Depression Scale. Acta Psychiatr Scand. 1983;67(6):361-370.

24. Ost LG. Applied relaxation: description of a coping technique and review of controlled studies. Behav Res Ther. 1987;25(5):397-409.

25. Roxendal G. Body Awareness Therapy and Body Awareness Scale: Treatment and Evaluation in Psychiatric Physiotherapy [Doctoral thesis]. Göteborg: Department of Psychiatry, University of Gothenburg; 1985.

26. Vernon H, Mior S. The Neck Disability Index: a study of reliability and validity. J Manipulative Physiol Ther. 1991;14(7):409-415.

27. Helmerson Ackelman B, Lindgren U. Validity and reliability of a modified version of the Neck Disability Index. $J$ Rehabil Med. 2002;34(6):284-287.

28. Altmaier E, Russell D, Kao C, Lehmann T, Weinstein J. Role of selfefficacy in rehabilitation outcome among chronic low back pain patients. J Couns Psychol. 1993;40:335-339.

29. Denison E, Asenlof P, Lindberg P. Self-efficacy, fear avoidance, and pain intensity as predictors of disability in subacute and chronic musculoskeletal pain patients in primary health care. Pain. 2004;111(3):245-252.

30. Rosenstiel AK, Keefe FJ. The use of coping strategies in chronic low back pain patients: relationship to patient characteristics and current adjustment. Pain. 1983;17(1):33-44.
31. Jensen IB, Linton SJ. Coping Strategies Questionnaire: reliability of the Swedish version of the CSQ. Scand J Behav Ther. 1993;22:139-145.

32. Waddell G, Newton M, Henderson I, Somerville D, Main CJ. A FearAvoidance Beliefs Questionnaire (FABQ) and the role of fear-avoidance beliefs in chronic low back pain and disability. Pain. 1993;53(2): $157-168$.

33. Jensen MP, Karoly P. Self-Report Scales and Procedures for Assessing Pain in Adults. New York, NY: Guilford Press; 1992.

34. Polit DF. Nursing Research: Principles and Methods. Philadelphia, PA: Lippincott Williams \& Wilkins; 2004.

35. Gustavsson C, von Koch L. Applied relaxation in the treatment of longlasting neck pain: a randomized controlled pilot study. J Rehabil Med. 2006;38(2):100-107.

36. Weiss RE. Modeling Longitudinal Data. New York, NY; London: Springer; 2005.

37. Tabachnick BG, Fidell LS. Using Multivariate Statistics. 5th ed. Boston, MA: Pearson Education. Allyn and Bacon; 2007.

38. Mercado AC, Carroll LJ, Cassidy JD, Cote P. Passive coping is a risk factor for disabling neck or low back pain. Pain. 2005;117(1-2):51-57.

39. Jensen MP, Nielson WR, Kerns RD. Toward the development of a motivational model of pain self-management. J Pain. 2003;4(9):477-492.

40. Jensen MP, Nielson WR, Turner JA, Romano JM, Hill ML. Changes in readiness to self-manage pain are associated with improvement in multidisciplinary pain treatment and pain coping. Pain. 2004;111(1-2):84-95.

41. Sullivan M, Adams H. Psychosocial treatment techniques to augment the impact of physiotherapy interventions for low back pain. Physiother Can. 2010;62(3):180-189.

42. Sullivan MJ. Toward a biopsychomotor conceptualization of pain: implications for research and intervention. Clin J Pain. 2008;24(4):281-290.

43. Kovacs FM, Abraira V, Zamora J, et al; Kovacs-Atención Primaria Group. Correlation between pain, disability, and quality of life in patients with common low back pain. Spine (Phila Pa 1976). 2004;29(2):206-210.

44. Campbell CM, Edwards RR. Mind-body interactions in pain: the neurophysiology of anxious and catastrophic pain-related thoughts. Transl Res. 2009;153(3):97-101.

45. Wall PD. Pain in the brain and lower parts of the anatomy. Pain. 1995;62(3):389-393.

46. Ochsner KN, Gross JJ. The cognitive control of emotion. Trends Cogn Sci. 2005;9(5):242-249.

47. Bussing A, Ostermann T, Neugebauer EA, Heusser P. Adaptive coping strategies in patients with chronic pain conditions and their interpretation of disease. BMC Public Health. 2010;10:507.

48. Ylinen J, Hakkinen A, Nykanen M, Kautiainen H, Takala EP. Neck muscle training in the treatment of chronic neck pain: a three-year follow-up study. Eura Medicophys. 2007;43(2):161-169.

49. Kazdin AE. Research Design in Clinical Psychology. 4th ed. Boston: Allyn \& Bacon Pearson Education; 2003.

50. Breivik H, Collett B, Ventafridda V, Cohen R, Gallacher D. Survey of chronic pain in Europe: prevalence, impact on daily life, and treatment. Eur J Pain. 2006;10(4):287-333.

51. Rhodes RE, Plotnikoff RC, Courneya KS. Predicting the physical activity intention-behavior profiles of adopters and maintainers using three social cognition models. Ann Behav Med. 2008;36(3):244-252.

52. Lee H, Hubscher M, Moseley GL, et al. How does pain lead to disability? A systematic review and meta-analysis of mediation studies in people with back and neck pain. Pain. 2015;156(6):988-997.

53. Van Liew C, Brown KC, Cronan TA, Bigatti SM, Kothari DJ. Predictors of pain and functioning over time in fibromyalgia syndrome: an autoregressive path analysis. Arthritis Care Res (Hoboken). 2013;65(2):251-256.

54. Nicholson RA, Hursey KG, Nash JM. Moderators and mediators of behavioral treatment for headache. Headache. 2005;45(5):513-519.

55. Damush TM, Weinberger M, Perkins SM, et al. The long-term effects of a self-management program for inner-city primary care patients with acute low back pain. Arch Intern Med. 2003;163(21):2632-2638.

56. Bandura A. Self-efficacy: toward a unifying theory of behavioral change. Psychol Rev. 1977;84(2):191-215.

57. Bandura A. Self-Efficacy: The Exercise of Control. Basingstoke: W. H. Freeman; 1997. 
58. Bandura A. Health promotion by social cognitive means. Health Educ Behav. 2004;31(2):143-164.

59. Michie S, Richardson M, Johnston M, et al. The behavior change technique taxonomy (v1) of 93 hierarchically clustered techniques: building an international consensus for the reporting of behavior change interventions. Ann Behav Med. 2013;46(1):81-95.

60. Baldwin JD, Baldwin JI. Behavior Principles in Everyday Life. 4th ed. Upper Saddle River, NJ: Prentice Hall; 2001.

61. Moseley GL, Butler DS. Fifteen years of explaining pain: the past, present, and future. J Pain. 2015;16(9):807-813.
62. Westman A, Linton SJ, Theorell T, Ohrvik J, Wahlen P, Leppert J. Quality of life and maintenance of improvements after early multimodal rehabilitation: a 5-year follow-up. Disabil Rehabil. 2006;28(7):437-446.

63. Carson JW, Keefe FJ, Affleck G, et al. A comparison of conventional pain coping skills training and pain coping skills training with a maintenance training component: a daily diary analysis of short- and long-term treatment effects. J Pain. 2006;7(9):615-625.

64. Multon KD, Parker JC, Smarr KL, et al. Effects of stress management on pain behavior in rheumatoid arthritis. Arthritis Rheum. 2001;45(2): $122-128$.

\section{Publish your work in this journal}

The Journal of Pain Research is an international, peer reviewed, open access, online journal that welcomes laboratory and clinical findings in the fields of pain research and the prevention and management of pain. Original research, reviews, symposium reports, hypothesis formation and commentaries are all considered for publication.
Dovepress

The manuscript management system is completely online and includes a very quick and fair peer-review system, which is all easy to use. Visit http://www.dovepress.com/testimonials.php to read real quotes from published authors. 